\title{
Erratum to: Estimating occupancy of the Vulnerable northern tiger cat Leopardus tigrinus in Caatinga drylands
}

\author{
Paulo Henrique Marinho ${ }^{1}$ - Daniel Bezerra ${ }^{1}$ - Marina Antongiovanni ${ }^{1}$. \\ Carlos Roberto Fonseca ${ }^{1}$ - Eduardo Martins Venticinque ${ }^{1}$
}

Published online: 4 October 2017

(C) Mammal Research Institute, Polish Academy of Sciences, Białowieża, Poland 2017

\section{Erratum to: Mamm Res}

https://doi.org/10.1007/s13364-017-0330-4

The original version of this article, unfortunately, contained an error.

In the "Results" section of the above article originally published with an error. Originally reading "...significant lack of fit (test statistic $=144.83, p=0.29$ )", this should instead have read "...significant lack of fit" $(\hat{\boldsymbol{c}}=\mathbf{0 . 9 5}$; Test statistic $=144.83$, $p=0.29)$ ". [bold text used to highlight problem area]

The original article was corrected.

The online version of the original article can be found at https://doi.org/ 10.1007/s13364-017-0330-4

Paulo Henrique Marinho phdmarinho@hotmail.com

1 Departamento de Ecologia, Centro de Biociências, Universidade Federal do Rio Grande do Norte, Natal, RN 59072-970, Brazil 